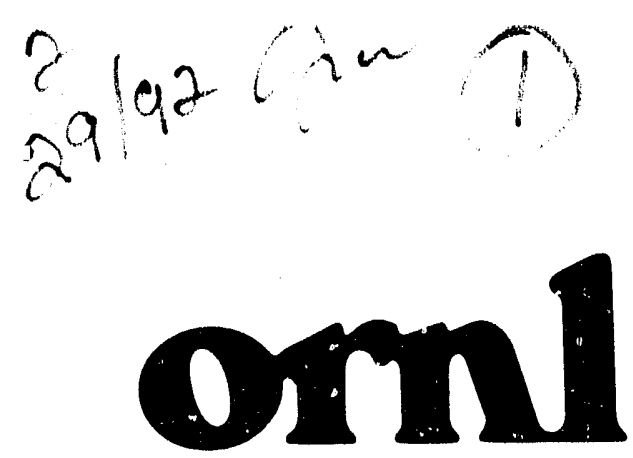

OAK RIDGE NATIONAL LABORATORY

MARTIN'MALUETRA

\section{A USER'S GUIDE FOR THE STARTER COMPUTER PROGRAM}

\author{
R. L. Childs \\ L. M. Petrie \\ N. F. Landers
}

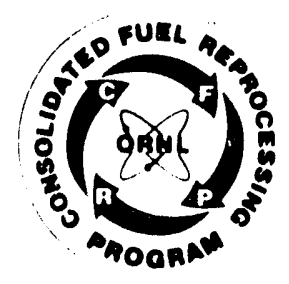

NOTICE

This Information can be utilized or distributed without restriction. It is provided to the Power Reactor and Nuclear Fuel Development Corporation (PNC) of Inpan under the terms of the Memorandum of Agreemeit for the Joint Collaboration in the Fleld of the Nuclear Fuel Cycls: LMR Reprocessing Technology between the United States Department of Energy and the PNC. 
This report has been reproduced directly from the best avallable copy.

Avallable to DOE and DOE contractors from the Office of Scientific and Techni. cal Information, P.O. Box 82, Oak Ridge, TN 37831; prices available from (615) 576-8401, FTS 626-8401.

This report was prepared as an account of work sponsored by an agency of the United States Government. Neither the United States Government nor any agency thereof, nor any of their employees, makes any warranty, express or implicd, or assumes any legal liability or responsibility for the accuracy. com pleteness, or usefulness of any information, apparatus, product, or process disclosed, or represents that its use would not intringe privately owned rights Reference herein to any specific commercial product, process, or service by trade name, trademark, manufacturer, or otherwise, does not necessarily constitute or imply its endorsement, recommendation, of favoring by the United States Government or any agency thereof. The views and opinions of authors expressed herein do not necessarity state or reflect those of the United States Government or any agency thereof. 


\section{A USER'S GUIDE FOR THE STARTER COMPUTER PROGRAM}

R. L. Childs, L. M. Petrie, and N. F. Landers

Computing and Telecommunications Division

Publisked - December 1991

Prepared for the Office of Facilities, Fuel Cycle, and Test Programs

Prepared by the

OAK RIDGE NATTONAL LABORATORY managed by MARTIN MARIETTA ENERGY SYSTEMS, INC.

for the DEPARTMENT OF ENERGY under contract DE-ACOS-84OR21400 


\section{CONTENTS}

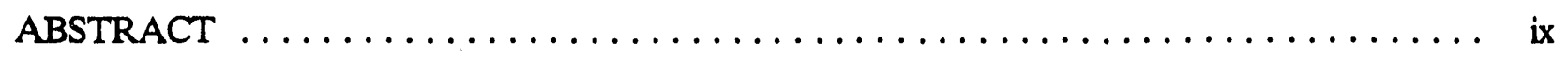

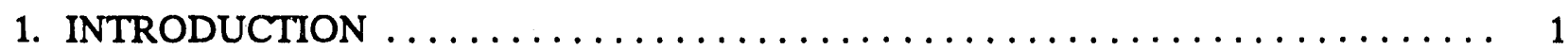

2. GENERAL COMMENTS ON MONTE CARLO CRITICALITY CALCULATIONS $\ldots \quad 2$

3. THE THEORETICAL BASIS FOR THE STARTER CODE $\ldots \ldots \ldots \ldots \ldots \ldots \ldots$

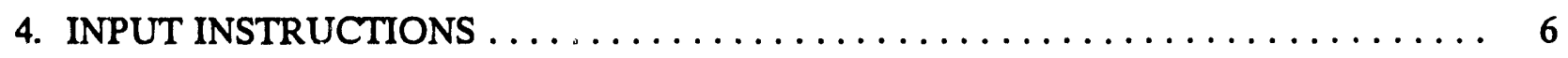

5. USER'S INFORMATION $\ldots \ldots \ldots \ldots \ldots \ldots \ldots \ldots \ldots \ldots \ldots \ldots \ldots \ldots \ldots \ldots \ldots$

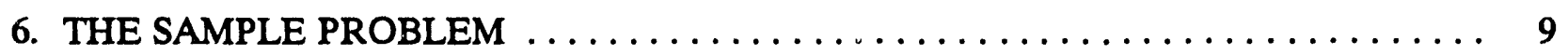

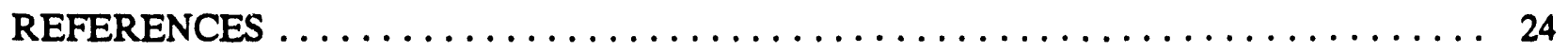




\section{LIST OF FIGURES}

$6.1 \quad$ The geometry of the sample problem $\ldots \ldots \ldots \ldots \ldots \ldots \ldots \ldots \ldots$

6.2 The geometry of the small initial calculation $\ldots \ldots \ldots \ldots \ldots \ldots \ldots \ldots$

6.3 The KENO V.a input for the small region geometry $\ldots \ldots \ldots \ldots \ldots \ldots \ldots$

6.4 STARTER input to prepare a starting guess for a subsequent large region

KENO V.a calculation using the restart file from a KENO V.a small

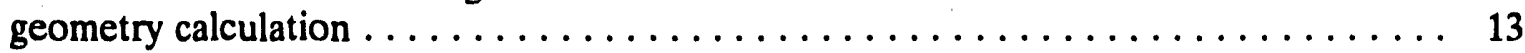

6.5 The KENO V.a input for the large geometry $\ldots \ldots \ldots \ldots \ldots \ldots \ldots$

6.6 Average $k_{\text {eff }}$ by generation using the STARTER source $\ldots \ldots \ldots \ldots \ldots$

6.7 Average $\mathrm{k}_{\text {eff }}$ by generation using an initial flat neutron source distribution $\ldots \ldots \ldots 16$

6.8 KENO $V . a$ input for the small cylinder $\ldots \ldots \ldots \ldots \ldots \ldots \ldots \ldots \ldots$

KENO $V .9$ input for the large cuboid $\ldots \ldots \ldots \ldots \ldots \ldots \ldots \ldots \ldots$

6.10 STARTER input for the separate component method $\ldots \ldots \ldots \ldots \ldots \ldots$

6.11 The output from STARTER $\ldots \ldots \ldots \ldots \ldots \ldots \ldots \ldots \ldots \ldots \ldots \ldots \ldots$

6.12 The fission production matrix from KENO V.a $\ldots \ldots \ldots \ldots \ldots \ldots \ldots \ldots$

$6.13 k_{\text {eff }}$ from STARTER and KENO V.a $\ldots \ldots \ldots \ldots \ldots \ldots \ldots \ldots \ldots$ 


\section{LIST OF TABLES}

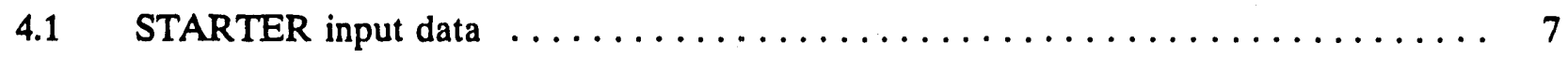

$6.1 k_{\text {efr }}$ from STARTER and KENO V.a $\ldots \ldots \ldots \ldots \ldots \ldots \ldots \ldots \ldots \ldots \ldots$ 


\section{ABSTRACT}

The STARTER computer code is used to prepare a starting source distribution for the criticality computer code, KENO V.a. The input description and theoretical basis of the STARTER code are described in this user's guide. 


\section{INTRODUCTION}

The STARTER code is a computer program that prepares an initial estimate of the fission density distribution for use as input to the Monte Carlo criticality program, KENO V.a. ${ }^{1}$ This capability is needed in complicated geometries where the initial source selection methods, ordinarily used with KENO V.a, are likely to result in undersampling of important spatial regions. In this methodology, one or more simpler portions (e.g., vessels) of a complicated geometry (e.g., process ell containing many vessels) are analyzed using KENO V.a, and a restart file is generated. STARTER then reads the restart file or files and creates an output file containing the coordinates of starting locations of fission neutrons to be used as input to a subsequent KENO V.a calculation. For very complicated problems, the procedure can be repeated several times to gradually combine more and more parts of the problem into a single calculation.

In the special case where only one restart file is input, STARTER can be used to increase or decrease the number of neutrons per generation. The origin of the coordinate system can also be changed in order to be consistent with the way the geometry for the restart case is specified.

The method used to combine the fission sources from multiple geometries was adapted from the earlier work of Bucholz ${ }^{2}$ Bucholz's method uses the solid-angle matrix $k_{\text {eff }}$ method to calculate $k_{\text {eff }}$ for a large system of loosely coupled components after a KENO calculation is performed for each component. The method results in a matrix eigenvalue problem in which $k_{\text {eff }}$ is the eigenvalue and the sources in the components are the eigenvector. STARTER uses the eigenvector source distribution obtained by solving the eigenvalue problem to distribute the neutron source among the components. These equations are very simple and approximate. However, the starting guess for KENO V.a does not need to bu extremely good, because the KENO V.a calculation can correct for shortcomings in the initial source guess if the guess is roughly correct. The use of several steps to gradually calculate nore complicated geometries also makes these limitations less severe.

The development of the STARTER code was funded by the U.S. Department of Energy, Office of Defense Programs. Documentation of the code is funded by a U.S. Department of Energy and Power Reactor and Nuclear Fuel Development Corporation (PNC) of Japan Joint Collaboration Program in the Field of Nuclear Fuel Cycle: Liquid Metal Reactor Reprocessing Technology. In the United States, this collaboration program is managed by the Consolidated Fuel Reprocessing Program, Robotics and Process Systems Division of Oak Ridge National Laboratory. 


\section{GENERAL COMMENTS ON MONTE CARLO CRTTICALITY CALCULATIONS}

One way to define the criticality factor, $k_{\text {eff }}$, is in terms of generations of neutrons where the fission process is the event which separates the generations. This results in an iterative procedure in which an initial guess for the fission neutron source is used to obtain the solution to the neutron transport equation corresponding to this source. The resulting neutron flux is then used to obtain the next generation neutron source. This procedure will eventually converge to a series of solutions in which each successive solution is the previous solution multiplied by a constant. The constant is defined to be $k_{\text {eff }}$, and the neutron flux is referred to as the dominant eigenfunction or the fundamental mode of the system. The idealized procedure outlined here will always converge to a unique value of $k_{e f f}$, and the fundamental mode is a unique positive function once a normalization is defined.

Unlike this idealized procedure, Monte Carlo criticality calculations can encounter a difficulty that can result in incorrect values of $\mathbf{k}_{\text {eff }}$ for certain systems. To make matters worse, the incorrect value is likely to be low and, hence, not conservative for criticality safety purposes. The cause of this difficulty is a failure of the source neutrons in the Monte Carlo calculation to converge to a source corresponding to the fundamental mode. When the starting guess for the Monte Carlo calculation does not start enough neutrons in a high importance region, the calculation can proceed as if the high importance region does not exist. In the idealized case, more and more of the neutron source would appear in the region of highest importance in later generations. However, Monte Carlo calculations follow only a relatively small number of neutron histories per generation, and this can result in undersampling which prevents convergence to the fundamental mode.

G. E. Whitesides has written two papers ${ }^{3,4}$ in which he discusses difficulties with fission source convergence. One observation he makes is that if the region of highest mult lication can be established, it appears that eventual source convergence to the fundamental mode can be obtained by starting all neutrons in this region. He also observes that the best insurance against undersampling of array geometries is to increase the number of neutrons per generation as the array size increases. An adequate number of source neutrons is necessary to insure that the fundamental mode source distribution is adequately defined for each successive generation.

The important conclusion to draw from the discussion in this section is that geometrically complex Monte Carlo calculations must be started with a source distribution that is reasonably close to the fundamental mode distribution in the system. In particuliai, the starting guess must have a 
considerable number of source neutrons in the region of highest multiplication. Also, the number of histories per generation should be as large as reasonable to minimize the possibility of undersampling. Limits upon the number of histories per generation are imposed by the amount of memory available on the computer being used. The cost of the computer calculations may also limit the total number of histories calculated.

\section{THE THEORETICAL BASIS FOR THE STARTER CODE}

The purpose of the STARTER code is to provide a good starting source guess for a KENO V.a calculation. First consider the situation where the region of highest multiplication in a complicated system is known in advance. In this case, a smaller KENO V.a calculation can be performed which includes the region of highest multiplication but which may exclude other regions of lesser importance. The smaller case should be simple enough that one of the existing sourcestarting options available in KENO V.a (such as a flat source in all fissionable material or a single point source in the region of highest multiplication) is sufficient to converge the fundamental mode distribution of the simple case. The complicated system can then be calculated by the using the source distribution from the smaller case as the starting guess for the subsequent KENO V.a calculation. STARTER accomplishes this objective by reading a restart file written by the smaller KENO V.a case and writing a file containing starting points for the source neutrons to be used by the large KENO V.a case. Also, STARTER has the capability to account for an offiset in the Cartesian coordinate systems of the two geometries and to change the number of source particles per generation for the second case.

For extremely complex geometrical problems (such as a building that has many vessels containing fissile material), $k_{\mathrm{ef}}$ can be calculated by performing a sequence of KENO V.a calculations in which the geometrical region included in each successive calculation becomes larger and larger. In this mode of operation, STARTER is used to prepare the starting guess for each of the subsequent KENO V.a calculations. Using STARTER in this manner may be a very good approach for many criticality safety problems. However, one way this approach could fail would be if the wrong location was assumed for the region of highest multiplication. Even in this case, the KENO V.a calculations would often converge to the correct fundamental mode. An experienced analyst and 
peer review should assure that the region of highest reactivity, the hot spot, is properly sampled in the criticality safety analysis.

STARTER can also be used to prepare a starting guess when two or more regions of a complicated geometry have been analyzed using KENO V.a. In order to accomplish this, STARTER uses a computationally simple method based on solid angle and other approximations developed by Bucholz. ${ }^{2}$ To illustrate this method, consider a number of bodies (geometric regions) for which KENO V.a calculations have been performed and the restart files saved. The source guess for the initial generation assimmes an equal number of source neutrons in each body. A simple approximation based on the neutron multiplication factor for each body, the escape probability for each body, and all of the body-to-body (solid-angle) transmission probabilities represented in the form of a large matrix, then allows one to estimate the nexi generation source in each of the bodies, for each successive genuration. The source is renormalized to unity for each generation, and source iterations are performed until the process converges. This results in an estimate of $\mathbf{k}_{\text {eff }}$ for the combined system and the fraction of source neutrons born in each body.

Four explicit approximations are made to obtain the relationship between sources in successive generations. The first approximation is that each source neutron assigned to a body produces $k_{\infty}$ next-generation neutrons, where $k_{\infty}$ for each body is approximated by $k_{\text {eff }}$ of the body divided by $\boldsymbol{P}_{\boldsymbol{1}}^{N Z}$ (the nonleakage probability for the body obtained from the KENO V.a calculation). Second, it is assumed that the number of next-generation source neutrons for any body resulting from present-generation source neutrons in the same body is $\mathbf{k}_{\text {eff }}$ times the number of present-generation source neutrons. Third, it is assumed that the number of next-generation neutrons that leak from any body is the number produced in that body times $P_{l}^{L}$ (the leakage probability for that body). Finally, it is assumed that the fraction of these leakage neutrons that contribute to the nextgeneration source in another body is the fractional solid angle subtended by the other body as viewed from a point in the center of the source body. The equation relating successive generation sources based on these assumptions is

$$
S_{j}^{N}=s_{j} k_{j}+\sum_{i \sim j} s_{i} \frac{k_{i}}{P_{i}^{N L}} P_{i}^{L} f(i \rightarrow j),
$$

where 
$S_{j} \quad$ is the source in body $j$ in the present generation,

$S_{j}^{N}$ is the source in body $j$ in the next generation,

$k_{j} \quad$ is $k_{\text {eff }}$ for body $j$ alone,

$P_{i}^{N L}$ is the nonleakage probability for body $i$ obtained from a KENO V.a calculation of body $i$ alone,

$P_{i}^{L}=1-P_{i}^{N L}$ is the leakage probability for body $i$,

$f(i-j)$ is the solid angle subtended by body $j$ as viewed from the center of body $i$ divided by $4 \pi$, and

$\sum_{j} S_{j}^{N}$ is renormalized to the desired total (1.0) at the end of each iteration (i.e., after all $S_{j}$ have been updated but before the next iteration begins). There are a number of limitatic ns to Bucholz's method. However, it has been applied to a number of real-life problems ${ }^{2}$ and has generally given conservative estimates for increases in $k_{\text {eff }}$, where overestimates of $k_{\text {eff }}$ are considered conservative for criticality safety purposes. Perhaps the most nonconservative assumption is the use of escape probabilities based on a KENO V.a calculation of an isolated body. Most of the source neutrons in this calculation will tend to be near the region of maximum multiplication which may be near the center of the body. Thus, the escape probability based on this calculation may be relatively low. Interaction neutrons from other bodies may tend to interact near the surface of the body and have a much higher escape probability.

Note that shadowing and wall reflection are ignored in Bucholz's method, but shadowing and wall effects are properly considered in the subsequent detailed KENO V.a calculation. Bucholz's method will sometimes fail to locate the region of maximum multiplication when the region of maximum multiplication is not located in the body that has the largest $k_{\text {effr }}$. An example of this is shown in ject. 6. Therefore, STARTER should not be viewed as a black box which always provides a good starting guess for KENO V.a. Rather, the STARTER code should be viewed as an automated method for preparing starting guesses. The person performing the analysis must assure that the region of maximum multiplication has been found and properly modeled. This may require a number of analyses and careful study. 


\section{INPUT INSTRUCTIONS}

The information input to STARTER directly by the user is often very short. This occurs because most of the information required for the STARTER calculation is obtained from the restart data files read by STARTER. These restart files are written by KENO V.a calculations of individual components. The STARTER input is lengthy only when there is a large number of restart data files. The STARTER input consists of two data blocks. The first block allows the user to specify the values of six integer variables. This input is similar to the "READ PARAMETERS" data in KFNO V.a. Three of the integer variables have default values that are sufficient for most, if not all, problems and usually need not be specified by the user. The second data block consists of sets of data containing an integer viuiable specifying the FORTRAN unit number for a restart data file followed by three real variables which define the geometry offsets $(\Delta X, \Delta Y, \Delta Z)$ for that dataset relative to the new geometry $(X, Y, Z)$. A set of these four numbers is entered for each input data file to be read. KENO V.a style free-form input is used for this part of the input. Both blocks of data are ended with an "END" parameter. The STARTER input data is given in Table 4.1.

The $\mathrm{X}$ geometry offset for a dataset is the amount that must be added to the $\mathrm{X}$ coordinate of each source point from that dataset to obtain the $\mathrm{X}$ coordinate for the point in the new geometry. There are also $\mathrm{Y}$ and $\mathrm{Z}$ geometry offsets which are defined similarly. Note that the user can use data from a restart dataset at more than one geometry offset. For example, if unit 44 is to be used twice with geometry offsets of $(0.0,0.0,0.0)$ and $(0.0,0.0,2.5)$, and unit 45 is to be used once with an offset of $(130.0,25.2,50.3)$, and 500 starting points are to be written on unit 46 , the input data could be:

$\mathrm{NUM}=500$ OUT $=46 \mathrm{NRU}=3 \mathrm{END}$

$443^{*} 0.0442 * 0.02 .5 \quad 45130.025 .250 .3$

END 
Table 4.1 STARTER input data

\begin{tabular}{|c|c|c|}
\hline & & Data block 1 \\
\hline NUM= & num & Enter the number of neutrons to be started in the system. \\
\hline OUT $=$ & out & $\begin{array}{l}\text { Enter the unit number where the source neutrons are to be } \\
\text { witten. }\end{array}$ \\
\hline$N R U=$ & nru & $\begin{array}{l}\text { Enter the number of datasets from which source points are } \\
\text { to be chosen. }\end{array}$ \\
\hline NBK $=$ & nblk & $\begin{array}{l}\text { Number of blocks allocated for the first direct access unit, } \\
\text { default }=200 \text {. }\end{array}$ \\
\hline $\mathrm{LBK}=$ & lblk & $\begin{array}{l}\text { Length of each block allocated for the first direct access unit, } \\
\text { default }=512 \text {. }\end{array}$ \\
\hline LNG $=$ & lng & $\begin{array}{l}\text { Enter the number of words of storage to be allocated to the } \\
\text { program, default }=100,000 \text {. }\end{array}$ \\
\hline \multirow[t]{2}{*}{ END } & & $\begin{array}{l}\text { Terminate this data block with the word END. It should not } \\
\text { start in column } 1 \text { and should be preceded by at least one } \\
\text { blank. }\end{array}$ \\
\hline & & Data block 2 \\
\hline \multicolumn{3}{|c|}{ The following data are entered in order. NRU sets of data are required. } \\
\hline $\mathrm{N}(\mathrm{i})$ & & Enter the unit number containing the ith set of restart data. \\
\hline XOFF(i) & & $\begin{array}{l}\text { Enter the } \mathrm{X} \text { offset for starting points from the ith set of } \\
\text { restart data with respect to the origin of the new geometry. }\end{array}$ \\
\hline YOFF(i) & & $\begin{array}{l}\text { Enter the } Y \text { offset for starting points from the ith set of } \\
\text { restart data with respect to the origin of the new geometry. }\end{array}$ \\
\hline ZOFF(i) & & $\begin{array}{l}\text { Enter the } \mathrm{Z} \text { offset for starting points from the ith set of } \\
\text { restart data with respect to the origin of the new geometry. }\end{array}$ \\
\hline END & & Terminate this data block with the word END. \\
\hline
\end{tabular}




\section{USER'S INFORMATION}

There are two particularly important subroutines in STARTER which perform the two main functions of the code. These subroutines are LODATA and SELPTS. LODATA and the subroutines that it calls read the restart files to obtain the average $k_{\text {eff }}$, the leakage fraction, and geometric information for the individual bodies previously analyzed with KENO V.a, and performs the calculation described in Sect. 3 to obtain the fraction of the source to assign to each body. SELPTS and the subroutines that it calls read the restart files $t ?$ obtain the fission neutron starting points for each body and generates the output file based on the source probability distribution function.

Only the outermost geometric region for each body is used by STARTER for the purpose of calculating solid angles. This outermost region (unit) will usually be a cuboid, but cylinders and spheres are also allowed. The solid angle subtended by the outer unit is calculated using function subprograms developed by Bucholz. These are generally described in ref. 2 and employ the same analytic techniques used in the XSDOSE code. ${ }^{5}$

The selection of source points by STARTER is done by random sampling. This means that even when the fractional source for two bodies is the same, the number of source neutrons assigned to the two bodies may be different because of the random characteristics of the Monte Carlo method.

In order to obtain a restart file when running the initial KENO V.a cases, two parameters must be specified in the KENO V.a input. These are RES and WRS. RES is the number of generations between writing restart data. An adequate value for RES is the value of GEN, the number of generations to be run. WRS is the logical unit number for writing the restart data. Both RES and WRS must be nonzero to obtain the restart file.

To use the start file generated by STARTER in KENO V.a, the following start data should be included in the KENO V.a input file:

\section{READ START KDU $=$ nn END START}

where $\mathrm{nn}$ is the logical unit number for the file generated by STARTER.

One problem with using STARTER is how to incorporate the geometric descriptions for each body into the geometric description required for the overall system. One way to handle this difficulty is to have one model for the overall system in which each body within the system (which is to be 
included in the STARTER calculation) is a "UNIT" in the KENO V.a geometry input. Then by simply placing the word "GLOBAL" in the definition of that unit as in "GLOBAL UNIT 14," KENO V.a will consider that unit to be the entire system and ignore the rest of the geometric input which describes other parts of the overall system. This approach should minimize the possibility of inconsistent geometric descriptions.

After a KENO V.a calculation has been performed with a source guess from STARTER, the user should examine the output to see how the STARTER guess and the KENO V.a calculation compare. One option in KENO V.a that is useful for this is the matrix $\mathbf{k}_{\text {efl }}$ by unit location option (MKP=YES). When this option is used, the source vector by position is printed and can be compared with the STARTER source vector. The user will probably want to select CKU=NO in order to eliminate the printing of cofactor $k_{\text {eff }}$ by position. Another option that can be used with MKP is FMP = YES which causes fission production by position to be printed. These correspond roughly to the estimated fission production matrix in the STARTER formulation. Large differences between the more rigorous KENO V.a results and the approximate STARTER terms should be examined closely.

Matrix $\mathrm{k}_{\text {eff }}$ results can also be obtained by unit number as well as by location. The options to do this are $M K U=Y E S, C K U=N O$, and FMU =YES. Both types of matrix $k_{\text {eff }}$ can be calculated in the same run if desired.

\section{THE SAMPLE PROBLEM}

The sample problem is a hypothetical example chosen to demonstrate how to prepare STARTER input. It also illustrates some of the limitations of the STARTER methodology insofar as it violates one of the primary assumptions of the methodology (i.e., that the system be loosely coupled). A drawing of the geometry for this example problem is shown in Fig. 6.1. For simplicity, the geometry is uniform in the $z$ direction with a large height of $400 \mathrm{~cm}$. The problem consists of a small cylinder surrounded by four large cuboids. A concrete wall surrounds the cuboids. The volume of the cylinder is much smaller than the four cuboids. Uniform source sampling would result in only about $0.3 \%$ of the source neutrons being started in the cylinder.

One way to use STARTER is to first perform a KENO V.a calculation on a smaller geometric region which contains the region of highest multiplication. For this sample problem, the region of 


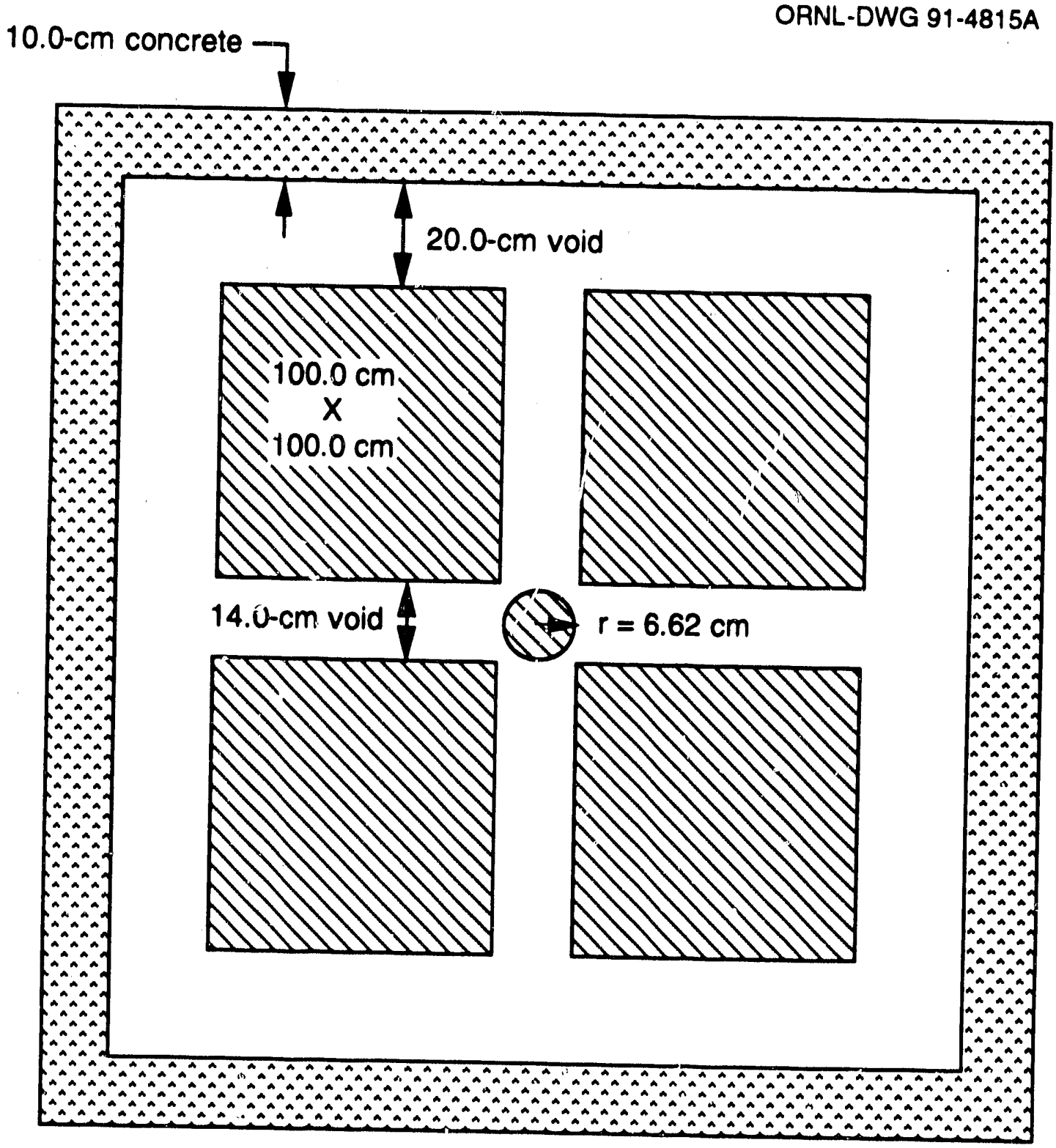

Fig. 6.1. The geometry of the sample problem. 
highest multiplication is most likely in the center of the geometry. A small geometry which includes this region is the region inside the dashed line in Fig. 6.2. The KENO V.a input for this case is shown in Fig. 6.3. Notice that WRS $=35$ and RES $=103$. This input causes a restart file to be written at the end of the KENO V.a run. Also notice that the origin of the calculation is located at point $A$ in Fig. 6.2. The origin is at point $A$ because of the KENO V.a geometry rule concerning arrays. This small region calculation has a high neutron leakage fraction of $42 \%$, and $k_{e f f}$ is 0.91 . The use of $\mathrm{MKU}=$ yes and $\mathrm{MKP}=$ yes results in the source vector being printed both by unit and by position. Seventy four percent of the source is in the central cylinder, which shows that the central cylinder is a region of high multiplication.

The STARTER input shown in Fig. 6.4 is used to generate a starting guess for the KENO V.a large geometry calculation. Unit 35 is read and unit 36 is written. The coordinate system offsets of $80 \mathrm{~cm}$ in the $\mathrm{x}$ and $\mathrm{y}$ coordinates are shown in Fig. 6.2 where point $\mathrm{B}$ is the origin of the large geometry.

The KENO V.a input for the large problem is shown in Fig. 6.5. The input parameter RDU set to 36 in the "start" data causes the code to read the file written by STARTER on unit 36 . The $k_{\text {eff }}$ for this case is $1.0026 \pm 0.0033$. Twenty seven percent of the final source is in the small cylinder which indicates that it is quite important despite its small size. Figure 6.6 shows the average $k_{\text {eff }}$ as a function of the number of genisrations run. Notice that the values of $k_{\text {eff }}$ start high and drop to a lower value as the fundamental mode converges. This is a desirable behavior because starting high means that many of the source neutrons were started in the area of high importance. This characteristic is conservative and avoids viderestimating reactivity. For comparison, this problem was also calculated using an initial flat neutron source distribution, rather than the STARTER sourcie. Figure 6.7 shows the average $k_{\text {eff }}$ by generation for this calculation. Notice that $k_{\text {eff }}$ starts low and takes longer to near the converged result than the STARTER-assisted calculation. The encouraging aspect of this result is that KENO V.a was able to obtain a good answer even with a source guess that undersampled the region of high multiplication. The danger of undersampling is that in some more difficult problems KENO V.a will not correct for the undersampling and an incorrect low result for $k_{\text {eff }}$ will be obtained.

Perhaps one's first approach to this sample problem would be to perform one KENO V.a calculation for the small cylinder and another for one of the four identical large cuboids. The STARTER methodology is then used to obtain a starting guess and also an estimate of $k_{e f r}$. This exercise illustrates problems encountered when using the STARTER code on components in a tightly 


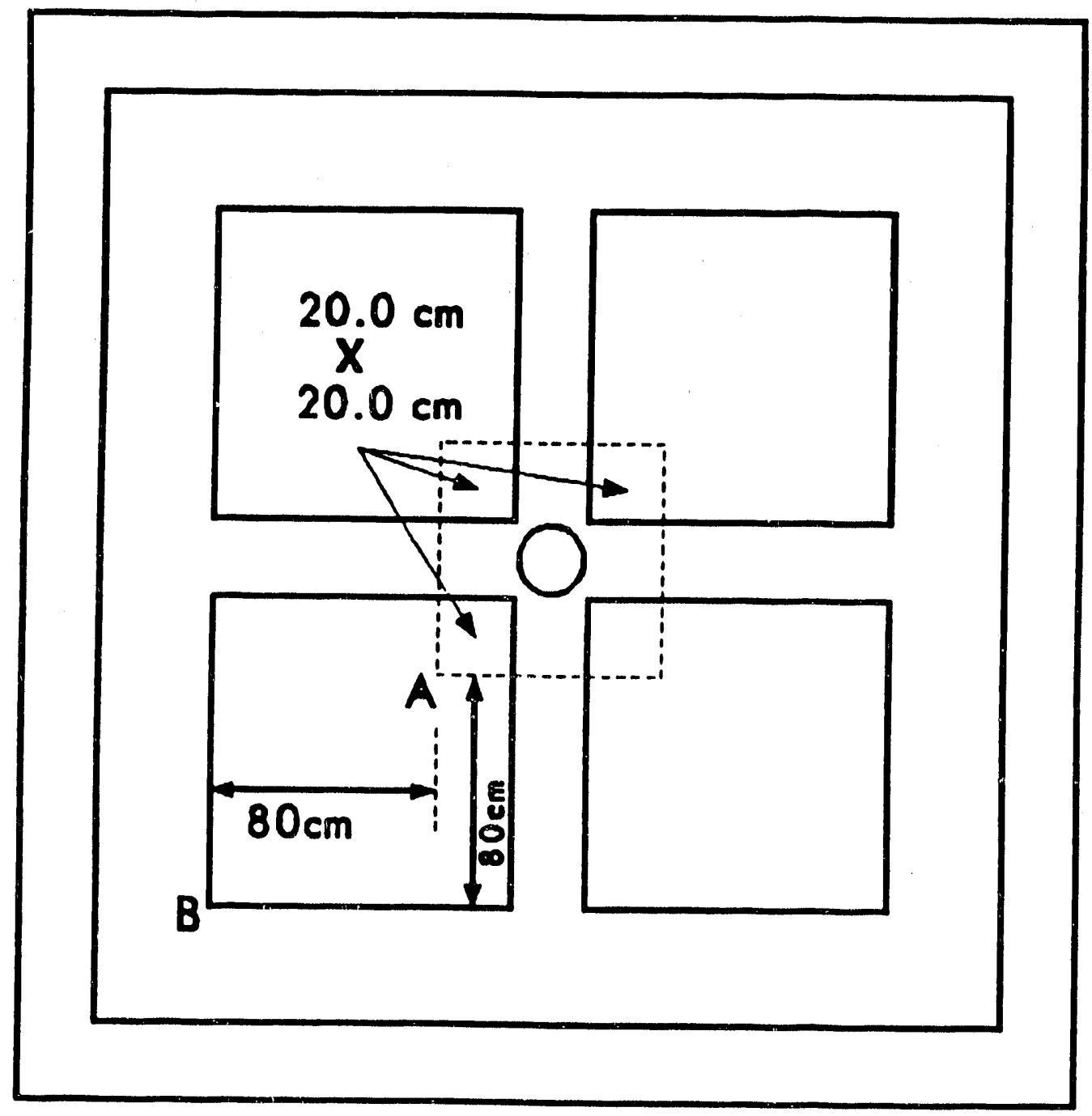

Fig. 6.2. The geometry of the small initial calculation. 


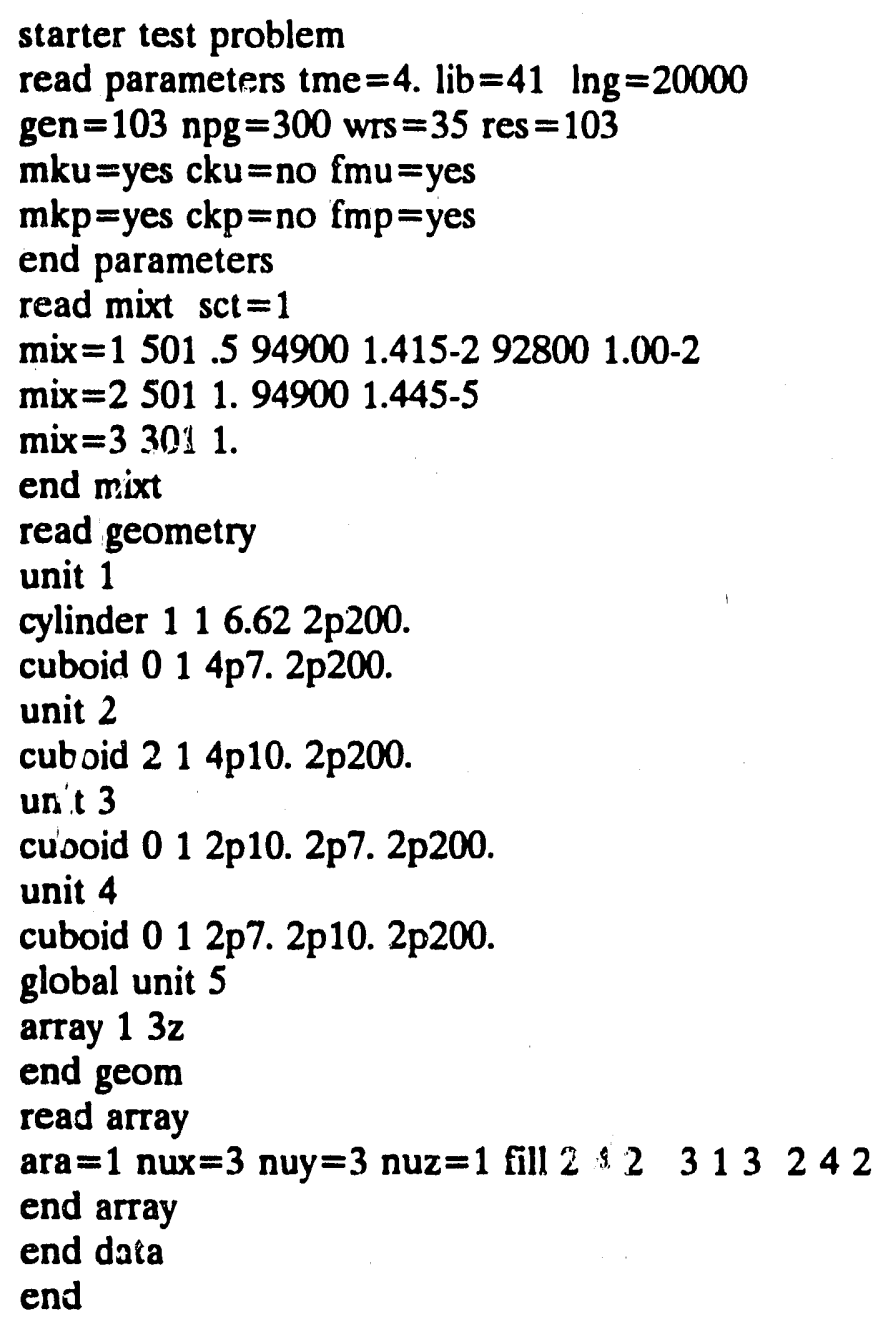

Fig. 6.3. The KENO V.a input for the small region geometry.

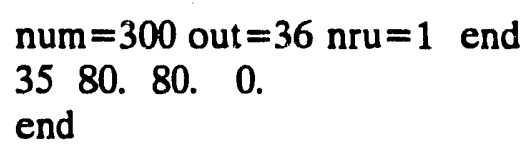

Fig. 6.4. STARTER input to prepare a starting guess for a subsequent large region KENO V.a calculation using the restart file from a KENO V.a small geometry calculation. 


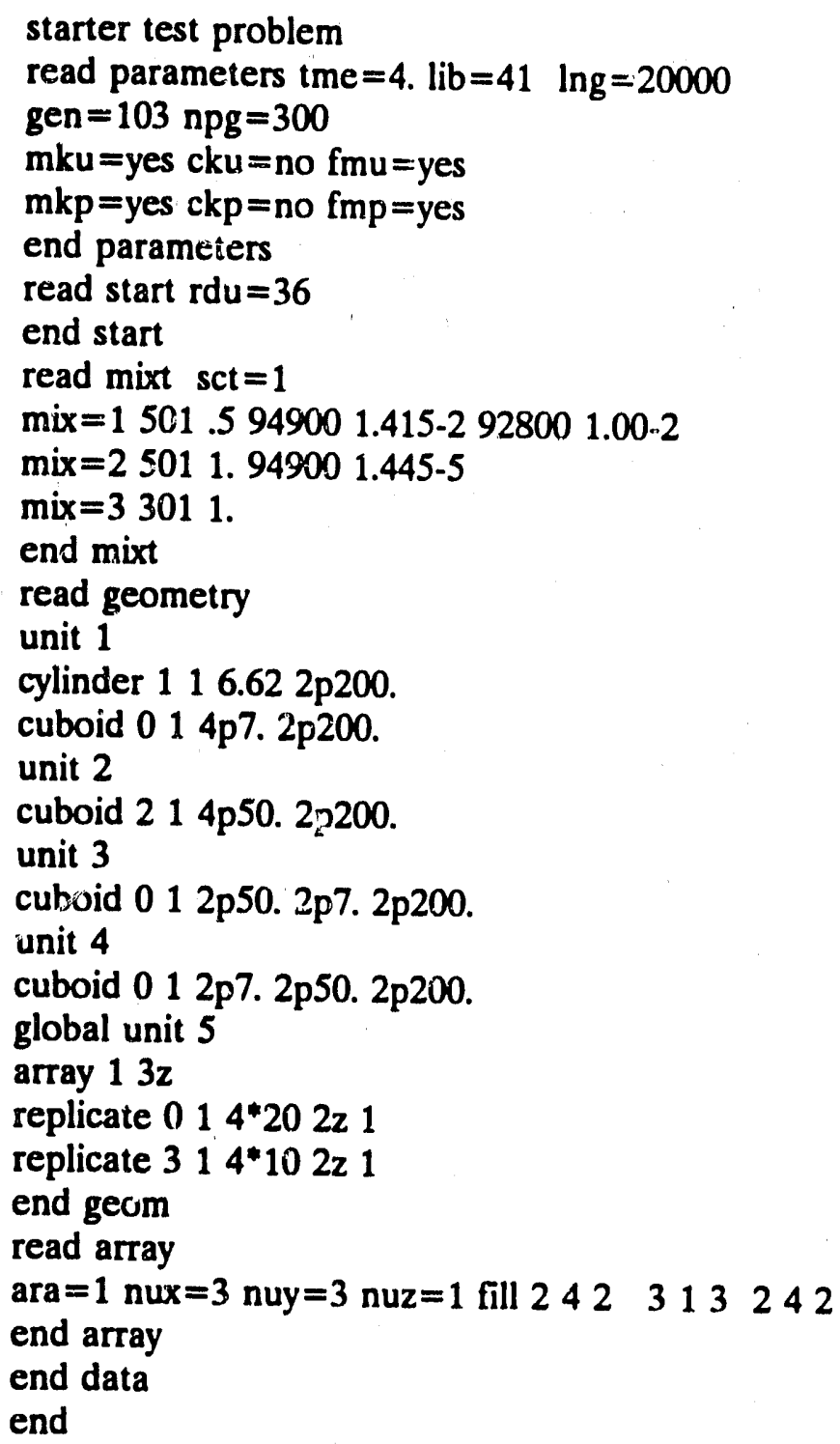

Fig. 6.5. The KENO V.a input for the large geometry. 
ORNL-DWG $91-4816$

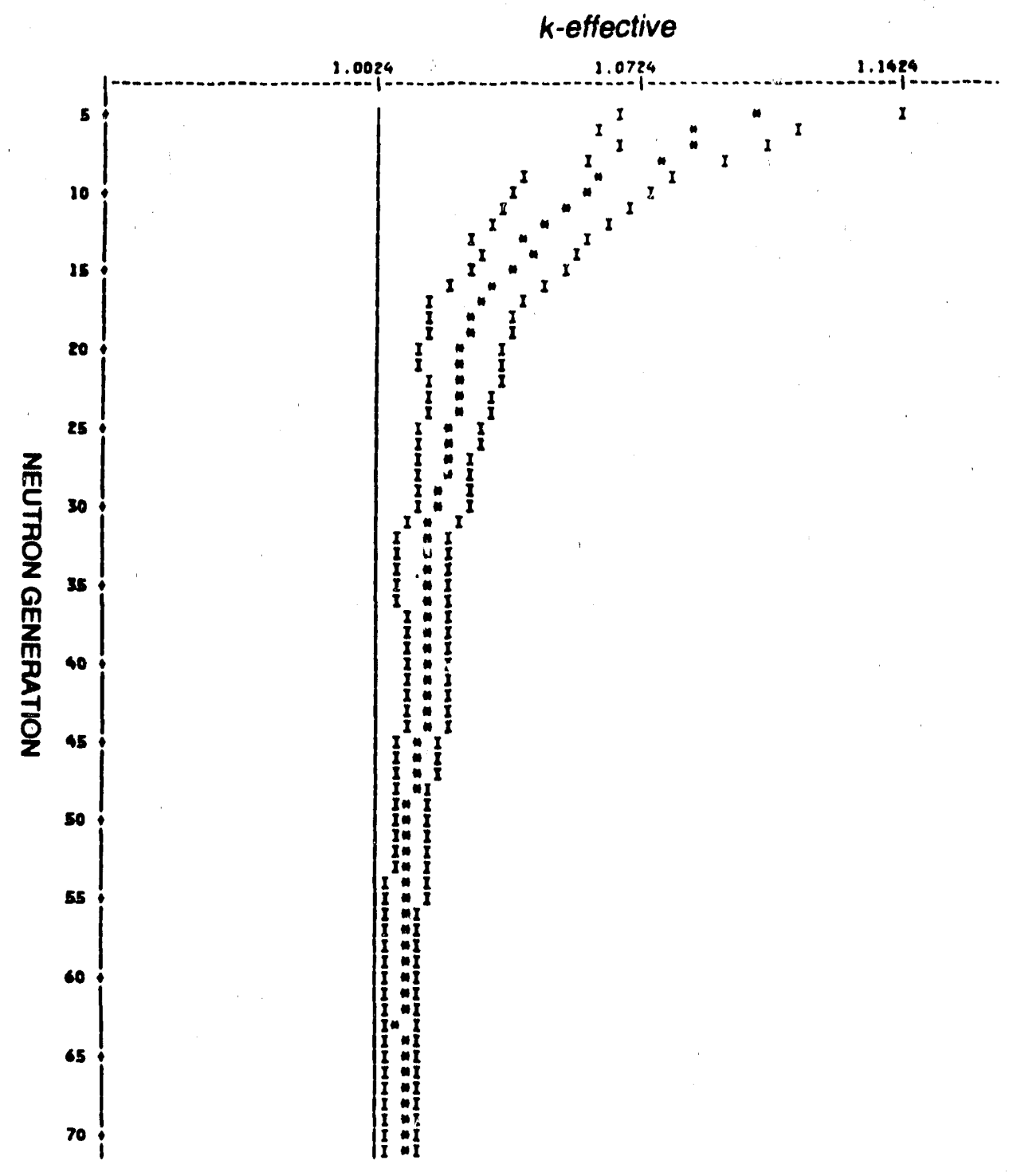

Fig. 6.6. Averge $k_{\text {eff }}$ by generation using the STARTER source. 
ORNL-DWG $91-4817$

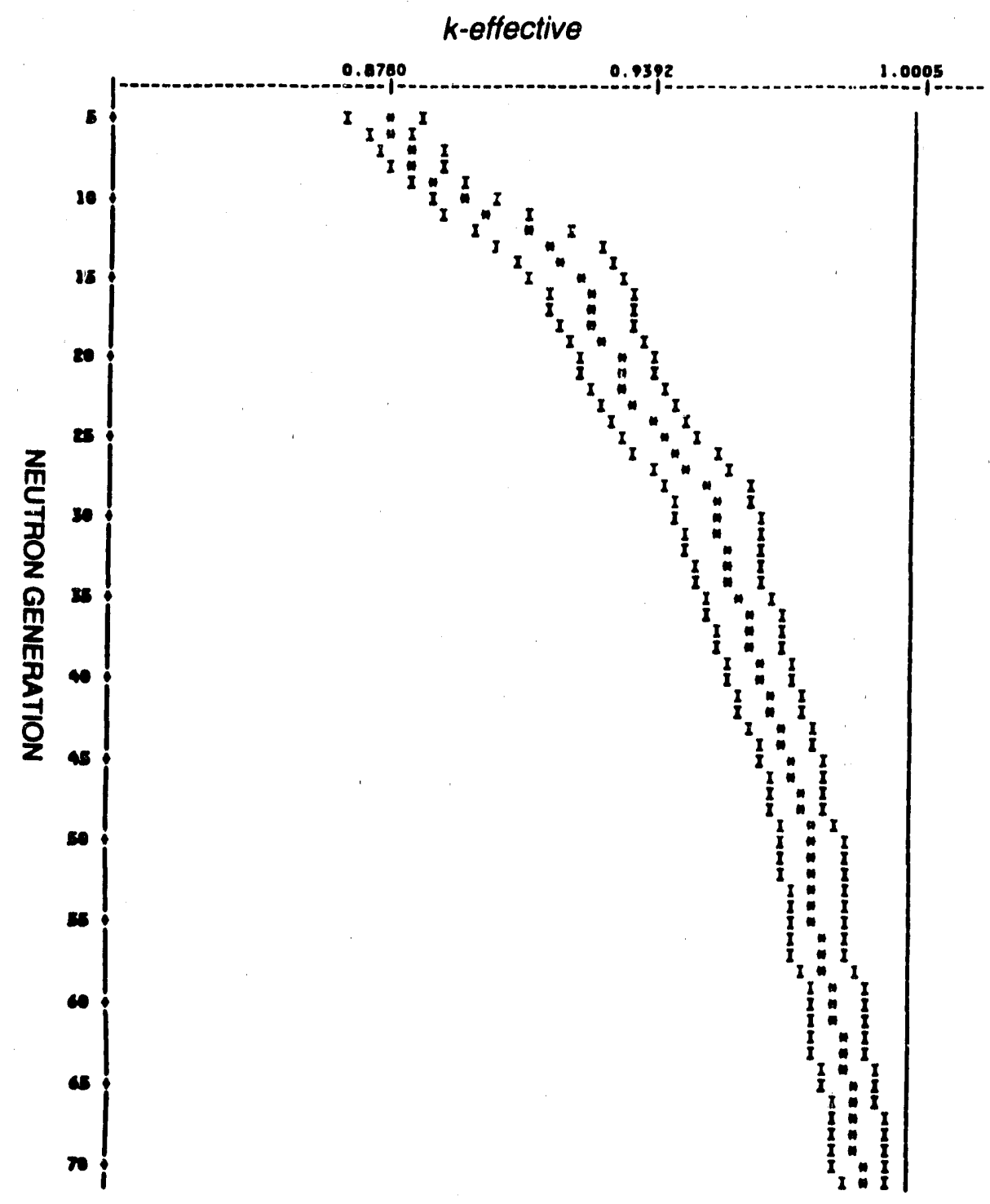

Fig. 6.7. Average $k_{\text {eff }}$ by generation using an initial flat neutron source distribution. 
coupled system fror which the methodology was never intended. Figures 6.8 and 6.9 show the KENO V.a input for the small cylinder and the large cuboid, and Fig. 6.10 shows STARTER input for this approach.

The STARTER input demonstrates how determining the offsets can be tricky. The '4P50.' in the cuboid description indicates that the $+x$ boundary of the cuboid is located at +50 ., the $-x$ boundary is located at -50 , the $+y$ boundary is +50 , and the $-y$ boundary is -50 . However, the 'read array end atray' input means that the coordinates are modified to conform to the KENO V.a convention for arrays which makes the coordinate for $(-x,-y,-z)$ become $(0,0,0$.$) . The input for the$ cylinder also contains 'read array end array' but this has no effect since the outermost geometry region is not a cuboid as required for arrays but is a cylinder. The origin for the cylinder is in the center of the cylinder. This explains why the $x$ and $y$ offsets are 107 instead of 100, and the $z$ offset is 200 instead of 0.0 . The cylinder could have been surrounded by a cuboid as was dore in Figs. 6.3 and 6.5 in order to make the offsets simpler, but this would change the STARTER result since the solid angles would be calculated for the outer cuboid rather than for the cylinder.

The output from the STARTER calculation is shown in Fig. 6.11. The first part of the output lists the input files read and the values for $k_{\text {eff }}$ STARTER reconstructed from the history files. The next quantity printed is the STARTER estimate of $k_{\text {eff }}$ for the combined system. Since the system is critical, the STARTER estimate of 0.8972 is quite low and nonconservative.

The next information printed is the STARTER estimate of the fission reduction matrix. A much better estimate of the fission production matrix (calculated by a KENO V.a run for the entire problem) is shown in Fig. 6.12. The two matrices are not immediately comparable because different indexing schemes are used. The largest discrepancy between the values in the two matrices is the number of next-generation fissions in the cylinder caused by neutrons born in the large cuboids. The STARTER estimate for this quantity is $1.38 E-3$. The KENO V.a matrix has a different value for each of the four cuboids. These are 5.74E-2, 5.52E-2, 5.51E-2, and 6.00E-2. The weighted average for this quantity, as obtained from the fission production by unit number matrix in the KENO V.a printout, is 5.70E-2. The STARTER result is a factor of 41 too low which probably explains why STARTER underestimated the amount of coupling present. One factor that contributes to this low value is the STARTER assumption that the leakage probability is the same as that of the isolated cuboid which is 0.06258 . For the coupled case, most of the fissions occur near the surface and, thus, have a much higher leakage probability. A second reason for the low value is the solid angle 


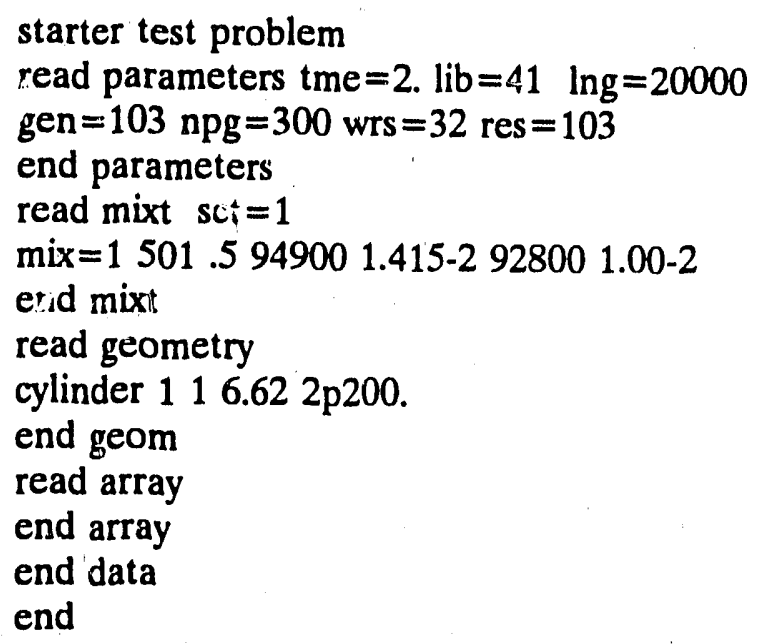

Fig. 6.8. KENO V.a input for the small cylinder.

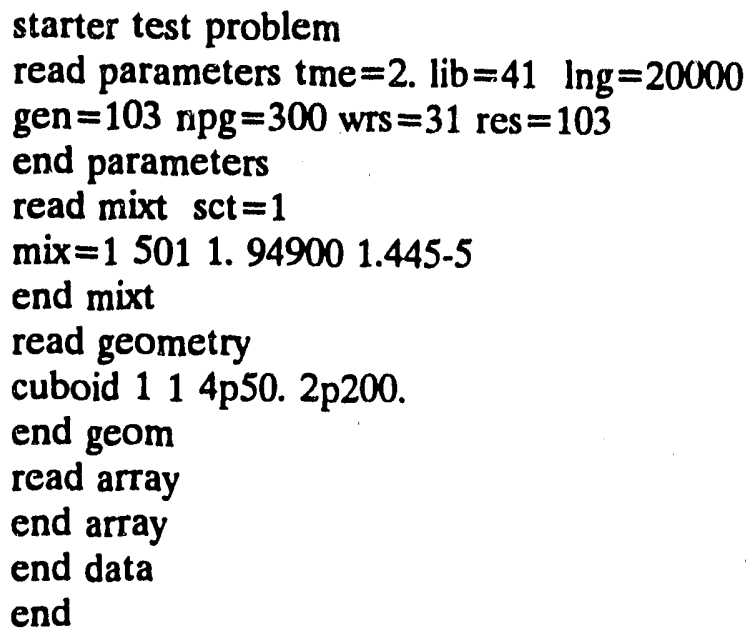

Fig. 6.9. KENO V.a input for the large cuboid. 


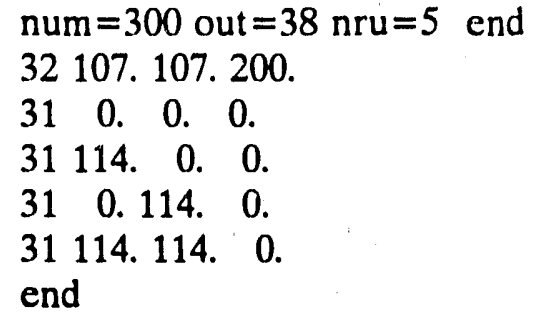

Fig. 6.10. STARTER input for the separate component method. 


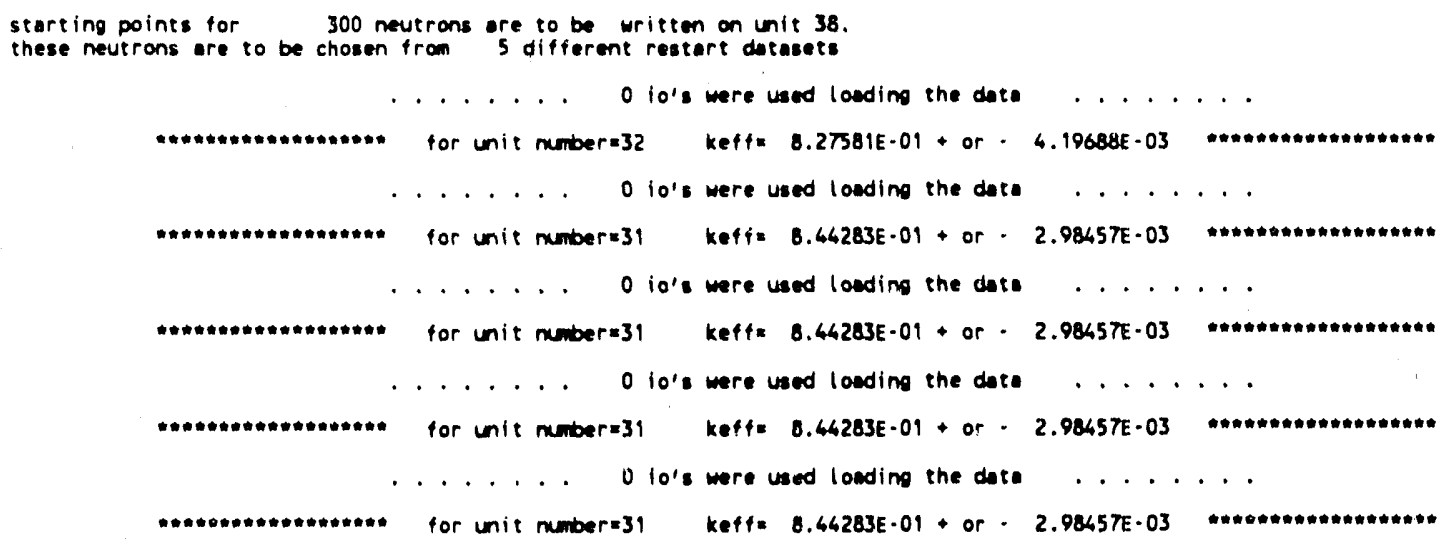

estimated k-effective $=0.8972$

est imated fission production metrix by restart index

$(i, j): 0$ is the estimated number of next generetion noutrons produced in index $j$ by a neutron by neutron born in index 1

( i, i) 0 is the estimeted nuber of next generetion neutrons produced in index i by a neutron by

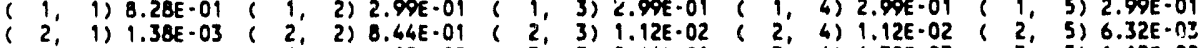

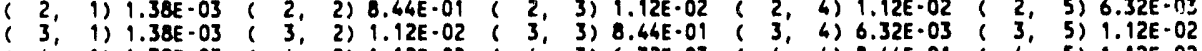

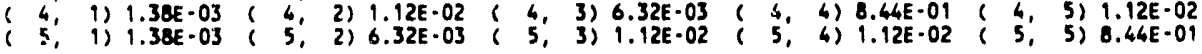

source probability vector

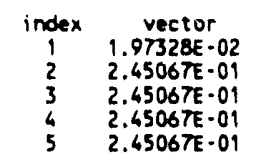

- total of 4 independent starting points wlll be chosem from unit muber 32.

- total of 67 independent aterting points will be chosen trom unit mubar 31 .

total of 79 independent sterting points will be chosen from unit muber 31.

78 independent sterting points will be chosen from unit nuber 31 .

- total of 72 independent starting points will be chosen from unit meber 31.

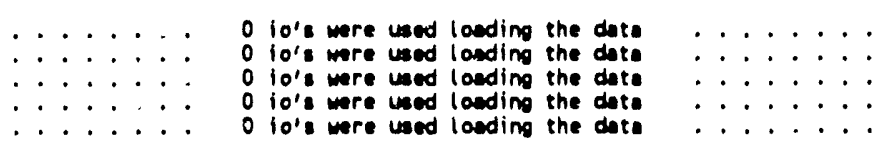

300 starting points were written on unit 38 in a binary formet for keno start type 6 .

Fig. 6.11. The output from STARTER. 


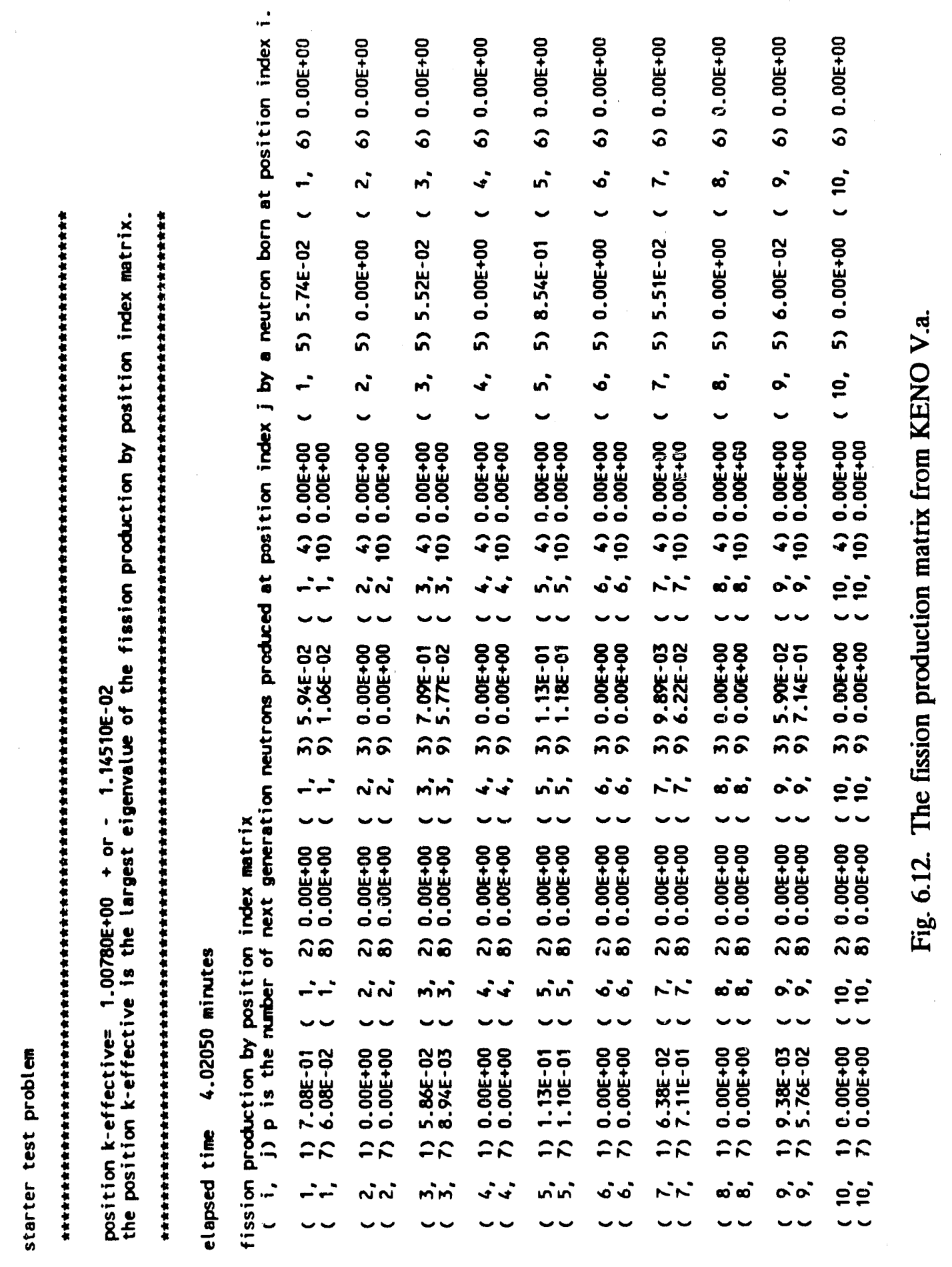


calculation which is done from a point in the center of the cuboid. Since many of the fissions occur much closer to the cylinder, the STARTER solid angle is low.

The next information printed by STARTER is the source probability vector. This result indicates that $1.97 \%$ of the neutrons should be started in the cylinder. The number that should be started in the cylinder based on the earlier KENO V.a calculation is $27 \%$. The STARTER value is too low and would cause the cylinder to be undersampled initially.

The final information printed by STARTER is the number of starting points chosen for each body. Notice that STARTER assigns a different number of neutrons to each cuboid even though they are identical. This occurs because STARTER uses Monte Carlo techniques to select the source.

The STARTER code will give better results for this system if the spacing between the components is increased to decrease coupling. This is demonstrated by the STARTER and KENO V.a results shown in Table 6.1 and Fig. 6.13 for four different spacings between the cuboids. The KENO V.a calculations used a starting guess in which all neutrons were started in the center of the cylinder. This is better than a flat guess for these problems. Notice that the STARTER estimates for $k_{\text {eff }}$ are much better for the wider spacing and actually overestimate $k_{\text {eff }}$ somewhat for the largest spacing which is the most loosely coupled system considered.

Table $6.1 k_{\text {en }}$ from STARTER and KENO V.a

\begin{tabular}{cll}
\hline Spacing & $k_{\mathrm{eff}}$ from STARTER & $k_{\mathrm{eff}}$ from KENO V.a \\
\hline $14 \mathrm{~cm}$ & 0.8972 & $1.0095 \pm 0.0033$ \\
$50 \mathrm{~cm}$ & 0.8813 & $0.8951 \pm 0.0030$ \\
$100 \mathrm{~cm}$ & 0.8684 & $0.8682 \pm 0.0029$ \\
$150 \mathrm{~cm}$ & 0.8608 & $0.8597 \pm 0.0023$ \\
\hline
\end{tabular}




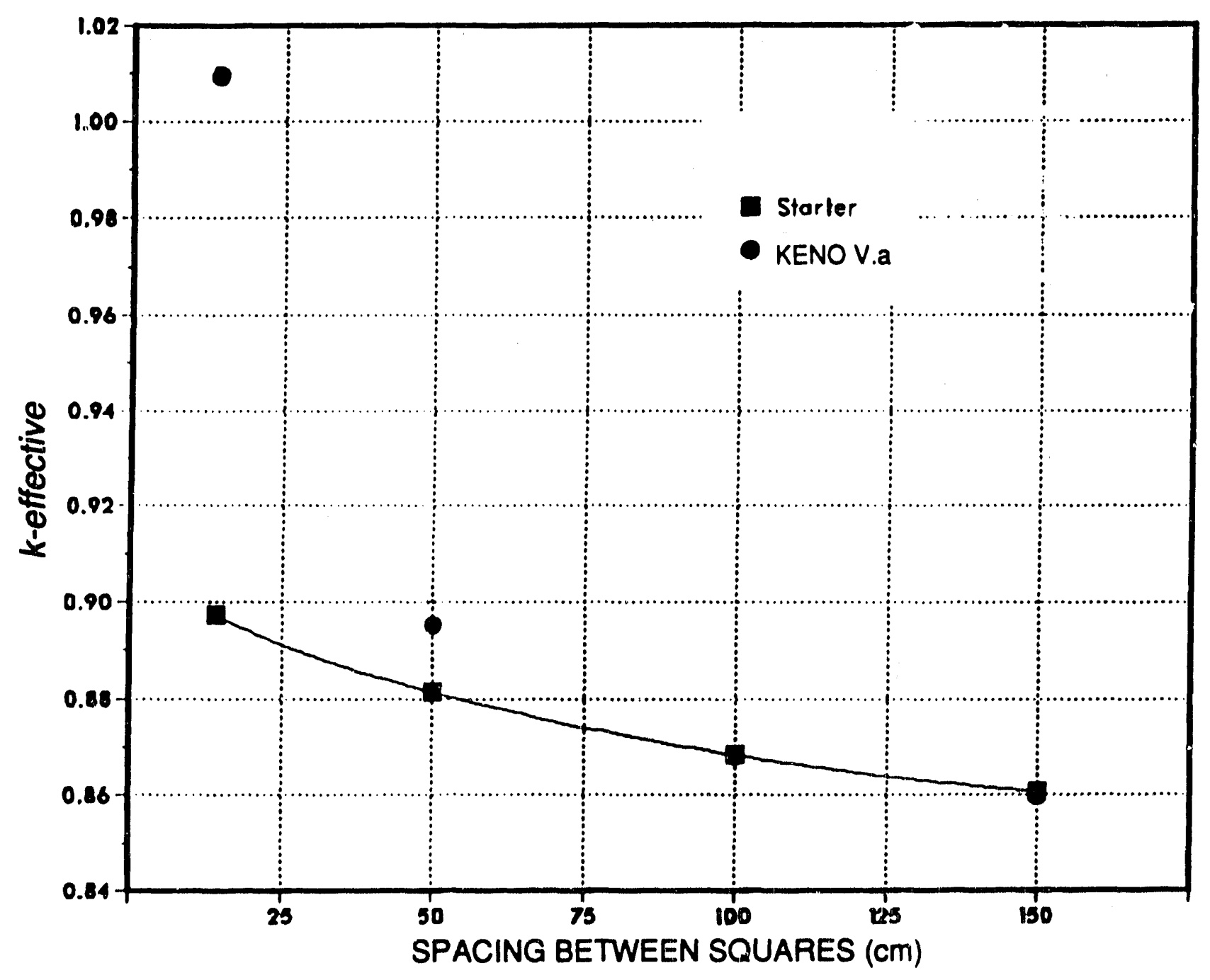

Fig. 6.13. $k_{\text {eff }}$ from STARTER and KENO V.a. 


\section{REFERENCES}

1. L. M. Petrie and N. F. Landers, "KENO V.a - An Improved Monte Carlo Criticality Program With Supergrouping," as described in Sect. F11 of SCALE: A Modular Code System for Performing Standardized Computer Analyses for Licensing Evaluation, INUREG/CR-0200, Rev. 4 (ORNL/NUREG/CSD-2/R4), Vol. II (draft February 1990).

2. J. A. Buchol?, Personal communication, August 1991.

3. G. E. Whitesides, "A Difficulty in Computing the k-effective of the World," Trans. Am. Nucl. Soc. 14, 680 (1971).

4. G. E. Whitesides, "Fission Source Convergence in Identical Arrays of Fissile Material," Trans. Am. Nucl. Soc. 45, 338 (1983).

5. J. A Bucholz, "XSDOSE: A Module for Calculating Fluxes and Dose Rates at Points Outside a Shield," as described in Sect. F11 of SCALE: A Modular Code System for Performing Standardized Computer Analyses for Licensing Evaluation, NUREG/CR-0200, Rev. 4 (ORNL/NUREG/CSD-2/R4), Vol. II (draft February 1990). 
ORNL/TM-11872

Dist. Category UC.526

\section{INTERNAL DISTRIBUTION}

1. E. C. Bradley

2. 3. A. Bucholz

3. W. D. Burch

4-8. R. L. Childs

9. J. E. Dunn, Jr.

10. R. W. Glass

11. M. J. Haire

12. C. M. Hopper

13-15. T. Ichimura

16. L. L. Jacobs

17. W. C. Jordan

18. R. T. Jubin

19. E. H. Krieg, Jr.

20. C. T. Kring

21-25. N. F. Landers

26. B. E. Lewis

27-29. S. A. Meacham

30. J. T. Mihalczo
31-35. L. M. Petrie

36. K. E. Plummer

37. C. W. Ricker

38. S. L. Schrock

39. G. R. Smolen

40. R. G. Upton

41. R. M. Westfall

42. G. E. Whitesides

43. M. G. Wilkerson, PNC-RC

44. H. R. Yonk

45-46. Laboratory Records

47. Laburatory Records ORNL.-RC

48-49. RPSD Publications Office

50. ORNL Patent Section

51. Central Research Library

52. Document Reference Section

\section{EXTERNAL DISTRIBUTION}

53. D. E. Bailey, Director, Division of Fuels and Reprocessing, Office of Facilities, Fuel Cycle, and Test Programs, NE-471, Department of Energy, Washington, DC 20545.

54. L. F. Blankner, Fusion and Nuclear Technology Branch, Energy Programs Division, Department of Energy, X-10 Site, P.O. Box 2008, Oak Ridge, Tennessec 37831-6269.

55. M. Kashihara, Director, Nuclear Fuel Cycle Development Division, Power Reactor and Nuclear Fuel Development Corporation, 9-13, 1-Chome, Akasaka, Minato-ku, Tokyo, Japan.

56. T. Kawata, Technical Coordinator, DOE/PNC Collaboration Program General Manager, Components and Materials Development Section, Reprocessing Technology Development Division, Tokai Works, Power Reactor and Nuclear Fuel Development Corporation, Tokai-mura, Ibaraki-ken, Japan Post No. 319-11.

57. T. Matsumoto, Technical Correspondent, Design Optimization of Facility, DOE/PNC Collaboration Program Senior Staff, Reprocessing Technology Development Division, Tokai Works, Power Reactor and Nuclear Fuel Development Corporation, Tokai-mura, Ibaraki-ken, Japan Post No. 319-11. 
58. W. H. McVey, Manager, LMR Reprocessing Projects, Division of Fuels and Reprocessing, Office of Facilities, Fuel Cycle, and Test Prograns, NE-471, Department of Energy, Washington, DC 20545.

59-68. H. Ojima, Deputy General Manager, Reprocessing Technology Development Section, Nuclear Fuel Cycle Development Division, Power Reactor and Nuclear Fuel Development Corporation, 9-13, 1-Chome, Akasaka, Minato-ku, Tokyo, Japan.

69. M. Ozawa, Technical Correspondent, Chemical Process Technology, DOE/PNC Collaboration Program, Components and Materials Development Section, Reprocessing Technology Development Division, Tokai Works, Power Reactor and Nuclear Fuel Development Corporation, Tokai-mura, Ibaraki-ken, Japan Post No. 319-11.

70. M. J. Rohr, Branch Chief, Fusion and Nuclear Technology Branch, Energy Programs Division, Department of Energy, X-10 Site, P.O. Box 20C8, Oak Ridge, Tennessee 37831-6269.

71. J. H. Saling, ORNL/CFRP On-Site Representative, Reprocessing Technology Development Division, Tokai Works, Power Reactor and Nuclear Fuel Development Corporation, Tokai-mura, Ibaraki-ken, Japan Post No. 319-11.

72. J. L. Scolt, DOE Representative, Power Reactor and Nuclear Fuel Development Corporation, Sankaido Building, 9-13, 1-Chome, Akasaka, Minato-ku, Tokyo, 107 Japan.

73. H. Takeda, Deputy Director, Reprocessing Technology Development Division, Tokai Works, Power Reactor and Nuclear Fuel Development Corporation, Tokai-mura, Ibaraki-ken, Japan Post No. 319-11.

74. Y. Tanaka, Technical Correspondent, Continuous Head-End Process Technology, DOE/PNC Collaboration Program, Deputy Manager, Components and Materials Development Section, Reprocessing Technology Development Division, Tokai Works, Power Reactor and Nuclear Fuel Development Carporation, Tokai-mura, Ibaraki-ken, Japan Post No. 319-11.

75. M. Tsutsumi, Director, Power Reactor and Nuclear Fuel Development Corporation, Washington Office, Suite 715, 2600 Virginia Avenue NW, Washington, DC 20037.

76-77. T. Yamaguchi, Director, International Division, Power Reactor and Nuclear Fuel Development Corporation, 9-13, 1-Chome, Akasaka, Minato-ku, Tokyo, Japan.

78. R. Yamamoto, Technical Correspondent, Advanced Remote Technology, DOE/PNC Collaboration Program Manager, Remote Maintenance Development Group, Components and Materials Development Section, Reprocessing Technology Development Division, Tokai Works, Power Reactor and Nuclear Fuel Development Corporation, Tokai-mura, Ibaraki-ken, Japan Post No. 319-11.

79. Office of Assistant Manager for Energy Research and Development, Oak Ridge Operations Office, Department of Energy, P.O. Box 2008, Oak Ridge, Tennessee 37831-6269.

80-150. Given distribution as shown in DOE/OSTI-4500 under UC-526, Consolidated Fuel Reprocessing Category. 

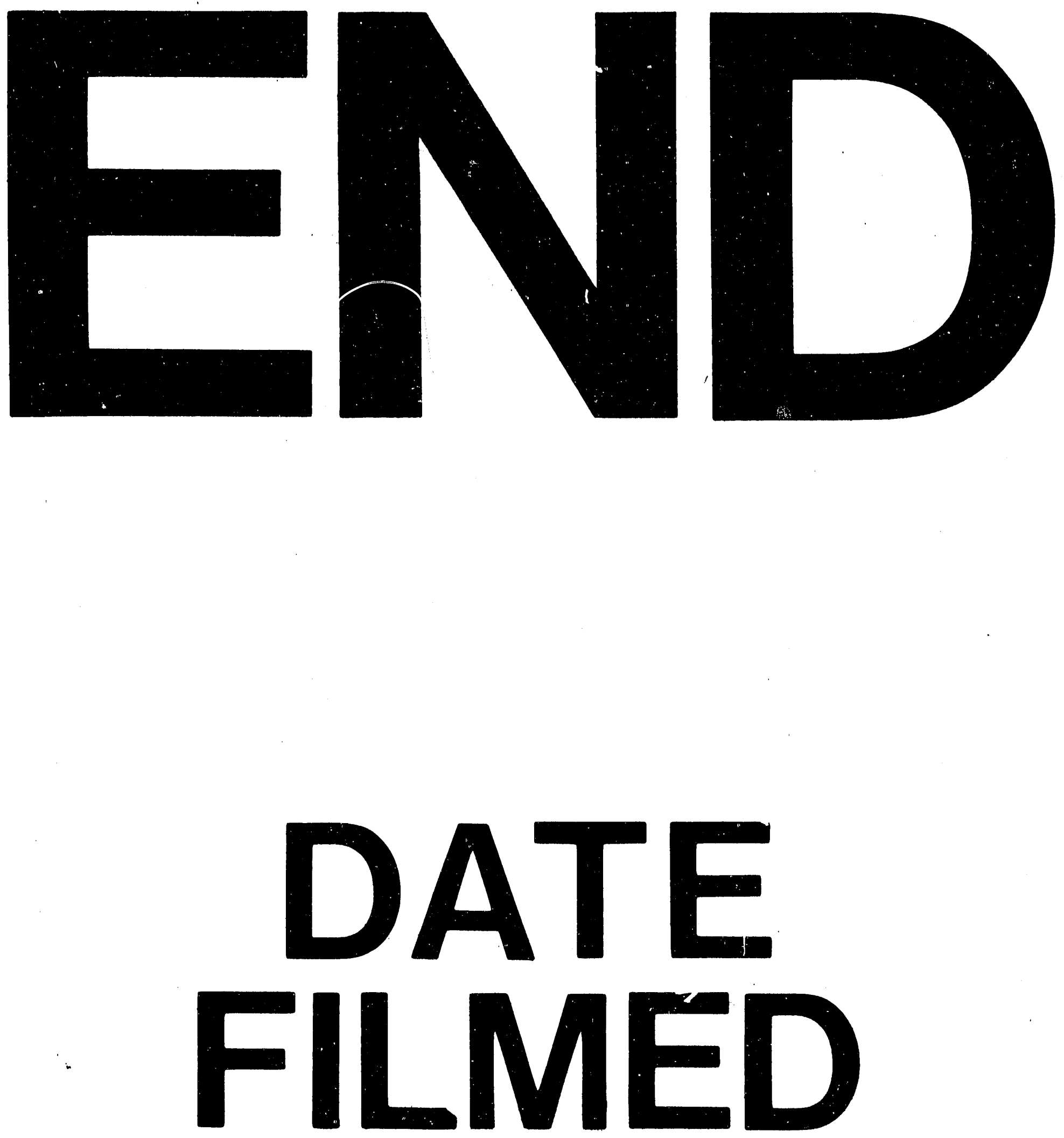

1

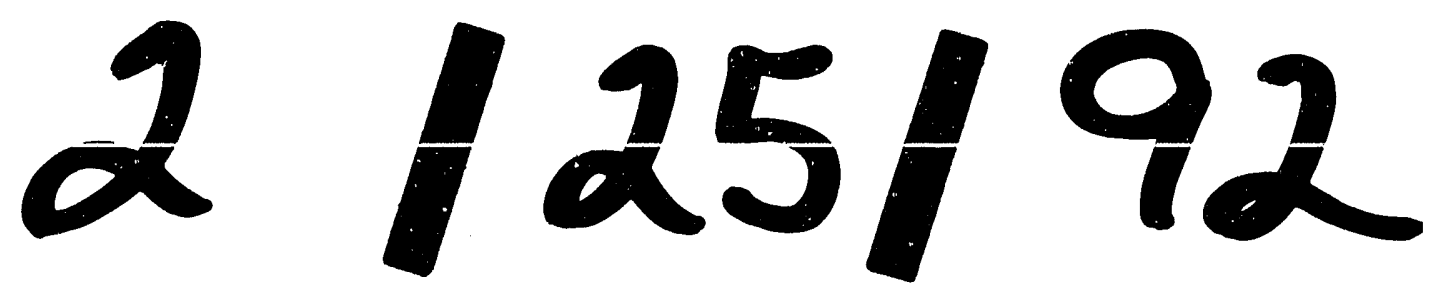


